\title{
TRÊS DÉCADAS DE RESISTÊNCIA FEMINISTA CONTRA O SEXISMO E A VIOLÊNCIA FEMININA NO BRASIL: 1976 a 2006
}

\section{Lourdes Bandeira*}

Resumo: Análise das principais ações e estratégias de resistência desencadeadas pelo movimento feminista que, nos últimos trinta anos, no Brasil, buscou erradicar a diversas formas de violência existentes contra a mulher. Discute-se por um lado, a violência como estratégia de controle sobre o corpo feminino e, por outro, a ineficácia da Lei $n^{\circ}$ 9.099/95. Com a implementação da Lei Maria da Penha, uma importante conquista legislativa e jurídica no combate à violência contra a mulher, evidenciam-se mudanças nas estratégias socioculturais e nos recursos jurídicos utilizados no País; entretanto, expressões de violência institucional continuam presentes na cultura e nas práticas jurídicas. Tais expressões são parte de uma lógica moral masculina que ainda modela os procedimentos dominantes e que se faz presente nas instituições e entre os agentes públicos, assim como nos espaços privados e na família. Enfim, no conjunto da sociedade brasileira.

Palavras-chave: resistência feminista, violência, gênero, cultura jurídica, sexismo, Lei Maria da Penha.Estou feliz

Hoje meu amor veio me visitar,

Me trouxe flores para me alegrar,

E com lágrimas pede para voltar.

Hoje o perfume eu não sinto mais

Meu amor já não me bate mais,

Infelizmente eu descanso em paz...

Refrão da música Rosas.

Conjunto: Atitude Feminina - Brasília-DF

\footnotetext{
* Professora titular do Departamento de Sociologia da Universidade de Brasília (UnB) e pesquisadora do Núcleo de Estudos e Pesquisas da Mulher (Nepem/UnB).
}

Recebido em 10 nov. 2008 e aprovado em 20 dez. 2008. 


\section{Introdução}

No Brasil, a resistência feminista contra a violência sofrida pelas mulheres acarretou mudanças históricas nos processos legislativos, institucionais e jurídicos. Essas mudanças foram iniciadas no período da ditadura militar, na década de 1970, quando, no cenário das demandas pela anistia política de centenas de homens e mulheres, vítimas da violência militar, segmentos do movimento feminista brasileiro se empenharam em denunciar a violência cometida contra as mulheres no próprio lar. Este processo de resistência se fortaleceu com várias estratégias de luta, dentre elas, a nominação da expressão "violência contra a mulher", seguida pela demanda por políticas públicas a fim de coibi-la.

A primeira resposta do Estado brasileiro às demandas foi efetivada com a criação da Delegacia Especializada de Atendimento a Mulher (DEAM) em 1985, em São Paulo, cujos impactos repercutiram, positivamente, nos segmentos menos privilegiados da sociedade.

Seguiu-se, nos anos 1990, a criação dos Juizados Especiais Cíveis e Criminais (JECRIMs), regidos pela Lei $n^{\circ}$ 9.099/95. Embora estes tivessem como principal característica tratar dos delitos gerais considerados de "menor potencial ofensivo", estimulando mecanismos de conciliação entre as partes envolvidas, foram "apropriados" pela evidência empírica da habitualidade das denúncias de violência contra as mulheres registradas nas DEAMs. As denúncias passaram a ser tratadas no âmbito dessa lei, ocasionando muitos equívocos, desde o desconhecimento de que a violência contra a mulher é estruturante das relações hierarquizadas entre os sexos, até decisões inadequadas, que, muitas vezes, acabaram por justificar uma violência social e jurídica (Campos, 2008). Isso ocasionou uma forte resistência por parte da militância feminista quanto à aplicação da Lei $n^{\circ}$ 9.099/95. 
A partir de 2000, a intensificação da luta pela democratização dos direitos humanos e pela cidadania impulsionou a criação da Secretaria Especial de Políticas para Mulheres, que se efetivou em 2003, e esteve presente na elaboração da nova legislação destinada a erradicar a violência contra as mulheres, fenômeno que ainda hoje se expressa em dados alarmantes.

A densa mobilização nacional das mulheres conseguiu também pressionar o Estado brasileiro, levando-o a aprovar, em 2006, a Lei ${ }^{\circ}$ 11.340, cunhada como Lei Maria da Penha. Essa Lei representa uma ruptura com o escopo restritivo do conteúdo das denúncias acolhidas nas DEAMs, condicionadas na ordem da violência doméstica, sem, no entanto, compreender a dinâmica e complexidade dos conflitos interpessoais que caracterizavam o cotidiano das mulheres (Suárez et al., 2002).

Foi na Conferência Mundial de Direitos Humanos, realizada em Viena, em 1993, que o Tribunal de Crimes contra as Mulheres expôs a necessidade de se inserir o direito à vida sem violência como indissociável da luta pelos Direitos Humanos no mundo, antecedendo a Declaração sobre a Eliminação da Violência contra a Mulher, aprovada pela ONU também em 1993. Esses eventos tiveram importância fundamental para a elaboração da Convenção para Prevenir, Punir e Erradicar a Violência contra as Mulheres, conhecida como Convenção de Belém do Pará, que definiu a violência contra a mulher como: “... qualquer ação ou conduta baseada no gênero, que cause morte, dano físico, sexual ou psicológico à mulher, tanto no âmbito público como no privado".

Por sua vez, a Convenção Interamericana, ratificada pelo Brasil em 1994, se constituiu no marco que teve papel fundamental para pressionar o Estado a lograr mudanças legislativas, demandando políticas públicas de prevenção e atenção às mulheres vítimas (cf. Herman, Barsted, 1999, 2006). ${ }^{1}$ 
A Lei Maria da Penha foi inspirada na Convenção Interamericana para Prevenir, Punir e Erradicar a Violência contra a Mulher (Convenção Belém do Pará), que ampliou a extensão dos repertórios conceituais relativos às múltiplas práticas da violência contra a mulher.

Assim, os momentos de resistência feminista instaurados no Brasil, oriundos do movimento social, inicialmente demandaram ações do Estado tanto pela via institucional-legislativa quanto pela via jurídica, os quais são analisados a seguir.

O objetivo deste texto é evidenciar os processos ocorridos nas três décadas de resistência das mulheres, dos quais algumas conquistas se efetivaram, seja pela persistente organização das mulheres nos movimentos sociais, seja pela atuação por meio das vias legislativas, jurídicas e institucionais. A maioria dos exemplos mencionados aqui foi retirada da mídia nacional impressa. Essa opção metodológica justifica-se porque as discursividades midiáticas, no geral, correspondem aos valores e às representações sociais presentes no senso comum, majoritariamente, em cada sociedade em relação aos homens e às mulheres, que acabam por incidir também nas atuações e práticas profissionais dos/as agentes públicos/as.

Cabe lembrar que as distintas expressões usadas no texto - violência contra a mulher, violência de gênero e violência interpessoal -, embora consideradas categorias com significados conceituais próprios, no geral são utilizadas com sentidos similares. $\mathrm{Na}$ análise utilizam-se essas três categorias, uma vez que a violência é dirigida contra a mulher, não simplesmente na condição de ser vítima, mas, sobretudo, por causar uma ruptura com a condição de humanidade da pessoa, atingindo sua integridade plena, causando dor, sofrimento e medo. Ancora-se, necessariamente, na existência de relações de poder assimétricas, de hierarquias, visíveis ou não, pois se trata, concomitantemente, de uma violência derivada de relações sociais de gênero produzidas historicamente, uma vez que 
a produção da masculinidade obedece a processos diferenciados dos que produzem a feminilidade (Segato, 2003).

Portanto, não se pode desconsiderar que já existe, com anterioridade, na expressão violência contra a mulher, uma ordem simbólica demarcada pela desigualdade que está presente e organiza o cotidiano da vida social, regido por assimetrias existentes entre homens e mulheres. Assim, a dimensão relacional de gênero, independentemente do tipo de vínculo que é mantido entre homens e mulheres, não pode ser dissociada de qualquer manifestação ou expressão de prática de violência, uma vez que potencializa as dessimetrias presentes tanto no contrato conjugal como na vida social em geral. Ou seja, nessa perspectiva, não pode haver dissociação entre as manifestações de violências estruturais e as violências interpessoais.

\section{O uso da violência como estratégia normativa do controle viril sobre os corpos femininos}

Entende-se aqui a categoria de resistência como compreendendo estratégias e dinâmicas de rejeição e de luta desencadeadas pelas mulheres contra padrões, papéis e normas de comportamentos culturais e sociais desiguais que lhes foram impostos e que hierarquizam os sexos. Assumiram uma resistência que não é feita pela contra-violência, mas pelo desejo de ações de mudanças e por lutas que as reconheçam como sujeitos, “... isto é, alguém dotado de direitos" (Chauí, 1986, p. 136).

Em sentido contrário, a performance masculina tem resistido aos processos de mudança, tentando preservar os modelos culturais e cognitivos que lhes garantem o status quo, as assimetrias em relação ao exercício do poder estabelecido no grupo, onde predominam práticas de hierarquia e de mando extensivas aos operadores do direito. 
Ainda hoje, tanto as ocorrências da violência interpessoal cotidiana, como os assassinatos violentos de mulheres, também denominados de feminicídios $^{2}$ por algumas autoras, se multiplicam para além do previsível e as características dos números fazem suspeitar que uma variedade de crimes de gênero se esconde por trás de estatísticas homogeneizadoras:

Entre $1^{\circ}$ de janeiro e dezembro/07, aproximadamente 369 mulheres foram mortas em Pernambuco. De 2002 a 2006, ocorreram 1.512 assassinatos de mulheres. São vítimas principalmente dos maridos, namorados e ex-companheiros. A maioria é pobre, negra e tem entre 15 e 24 anos, mesmo perfil dos homens vítimas de homicídio no Estado. Por sua vez, o relatório da USP/Comissão Teotônio Vilela, com base em dados do Sistema Único de Saúde, mostra que 1.428 mulheres foram mortas no Estado entre 2000 e 2004 (...) o índice é "altíssimo" -, se mantém estável: entre seis a sete mulheres em 100 mil habitantes são assassinadas por ano. A média nacional é de quatro por 100 mil (....), uma combinação de fatores explica a maioria dos homicídios no Estado: a cultura da honra, da masculinidade, aliada à alta disponibilidade de armas de fogo [...] são, em grande medida as causadoras.... (Lacerda, 2007, p. 25).

A habitualidade destes crimes remete, dentre as principais causas, aos crimes de poder: a natureza das relações interpessoais entre as partes; a banalização e a incorporação do uso sistemático da violência para a resolução de conflitos cotidianos, as diversas situações de hierarquias que permeiam as relações de afetividade. Conforme atestado pela natureza das relações interpessoais e sociais existentes, testemunhadas nas comunidades masculinas de origem, fragmentos de depoimentos colhidos nas pesquisas etnográficas, ilustram os argumentos usados pelos agressores-assassinos e seus advogados-defensores: "matei por amor, por zelo..."; "matei porque a queria demais..."; "matei para preservá-la da maledicência alheia..."; "matei porque estava fora de mim..."; "fiquei louco de ciúmes, não sabia o que estava fazendo..."; "matei para defender minha honra...". Na sociedade brasileira contemporânea ainda prevalece a equação: 
presença de relações hierárquicas que se sustentam na negação do outro, associada a relações de "honra e vergonha masculinas", que revelam a assimetria dos pares, herança das sociedades mediterrâneas colonizadoras. Essa equação é impulsionadora de relações interpessoais violentas.

Por sua vez, um recorrido pelas notícias presentes na mídia evidencia a força das dessimetrias de poder presentes nos jogos relacionais entre homens e mulheres não apenas simbolizadas, mas como uma ordem que sustenta o controle e a posse sobre o corpo feminino, revelados nas falas dos agressores. Estes exemplos justificam a complexidade das relações presentes nas violências praticadas: "ela queria sair de casa...; "ela era a minha mulher..."; "ela me pertence..."; "ela queria me deixar...", "ela pediu a separação... o divórcio”. Complementam esse cenário, os discursos de indignação por parte de homens que formam uma sorte de "irmandade masculina", presentes como "personalidades públicas masculinas e formadores de opinião", os quais repudiam as manifestações públicas levadas a cabo pelos movimentos feministas em favor das vítimas de violência.

Com as tais relações dessimétricas de gênero intercruzamse muitas outras, apresentando maior convergência e visibilidade as socioeconômicas, de raça/etnia, regionais, além de outras, abundantes nos registros policiais e no campo jurídico, uma vez que tais desigualdades não operam apenas na ordem simbólica, mas estruturam os lugares socioinstitucionais de homens e de mulheres em nossa sociedade.

$\mathrm{Na}$ linha analítica aqui adotada, a categoria "violência contra a mulher" embora revestida de complexidade conceitual, além de ser polissêmica e multicausal, é tomada como um instrumento de controle viril sobre os corpos femininos, que abriga um repertório de práticas diversas em intensidade e extensão. No geral, sob esta designação, são agrupados fenômenos e situações diversas: abusos 
verbais, físicos e emocionais, agressões e torturas, assédios e abuso sexual, estupro, privação de liberdade, escravidão sexual, incesto, heterossexualidade forçada, possessão forçada dos corpos femininos, maternidade imposta, abortamentos, mutilações físicas, assassinatos, e, enfim, outros crimes passionais e de honra, além de manifestações mais sutis, dissimuladas e envolventes, que sobrevivem por meio de chantagens, emoções e constrangimentos.

Do ponto de vista institucional e jurídico, tais situações eram referenciadas sob a denominação de violência contra $a$ mulher, e, portanto, agrupadas em poucos conjuntos classificatórios e modalidades, quando não em um conjunto único, sobretudo quando não havia materialidade explícita da prova (Soihet, 1989). Esse "agrupamento," realizado pela área da segurança pública, ou pelo judiciário, acabou por reproduzir a ausência de legitimidade e de reconhecimento dessas situações, assim como não garantia a aplicação da lei de maneira a desfazer as dessimetrias existentes (Brandão, 2006). A lei Maria da Penha interrompe com esse agrupamento porque opera na ordem simbólica, desestrutura os lugares sociojurídicos do agrupamento classificatório tradicional, e garante a especificidade de cada expressão de violência.

Marcadas a ferro é o título do livro de Castillo-Martín e Oliveira (2005) que traz na capa o rosto de uma mulher onde foram gravadas, a ferro quente, as iniciais do nome do seu dono-marido: HB. Aquele rosto ferrado representa milhares de outras que, engessadas em uma relação contratual de casamento, deixam de ser tidas como autônomas cidadãs, perdem ainda a liberdade de escolha e muitas não têm o explícito direito de existir fora de sua pertença contratual, a um dono-marido-patrão-masculino. Do contrário, acabam sendo mortas na guerra conjugal. Alguns exemplos:

Em 30 segundos, Alexandre matou a sua companheira, Daniela, com 29 facadas. Deflagrou uma facada por segundo, sendo que a última deixou cravada no peito de Daniela. Motivo confessado: 
tinha ciúmes e não aceitava o fim do relacionamento. Mais três mulheres foram assassinadas pelas mesmas razões esse [sic] ano [a autora refere-se aos meses de janeiro e fevereiro] no Distrito Federal. (Duarte, 2007, p. 25).

A ação durou alguns minutos. Três mulheres sentadas na escada de um prédio em Curitiba, quando uma delas foi atingida por um tiro no rosto. A vítima era comerciária, tinha 23 anos. $\mathrm{O}$ autor dos tiros tinha 56 anos e era seu ex-namorado. Declarou-se inconformado com o fim do namoro proposto pela vítima. ${ }^{3}$ (Mulher..., 2007, p. 5).

$\mathrm{O}$ crime, que ocorreu na Estância $\mathrm{V}$ do Condomínio Mestre d'Armas, em Planaltina (GO), chocou a todos pela brutalidade. A dona-de-casa Deoraci de Souza Oliveira, 28 anos, estava na casa do ex-marido, o também pedreiro Paulo Pereira de Souza, 24, com quem queria reatar o relacionamento. Os dois foram atacados por João Benedito Moreira de Carvalho [26]. Ele estava inconformado com o fim do relacionamento anunciado à tarde, pela namorada. $\mathrm{O}$ casal foi morto a facadas, na noite de domingo último. (Duplo..., 2008, p. 31).

O rompimento com a relação do casal pela mulher é visto como desobediência ao marido/companheiro e ruptura com a ordem social e com o contrato familiar. Há um "suposto" no horizonte do imaginário masculino de que a mulher que demanda a separação, em uma conjugalidade estável, no limite, troca o papel de esposamãe pelo de estar fora da heteronormatividade predominante. Fica cravada a representação social feminina da insubordinação, do revide, da desobediência à ordem familiar masculina hegemônica, e, quando é vista como "desviante" da regra heterossexual, corre o risco de receber uma nominação pejorativa. ${ }^{4}$

Ainda é conduta própria do homem latino, sentir-se possuidor da mulher e com direitos sobre ela. Para alguns, até o direito sobre a vida e morte da mulher. ${ }^{5}$ Há os que consideram tal comportamento como "natural", uma vez que a socialização viril potencializou as situações de dessimetrias na performance dos gêneros. Nessa 
direção tem-se observado, nos depoimentos de agressores, que estes decidem, em geral, assassinar a mulher, companheira ou namorada planejando sua ação com antecedência, de modo a pegá-la ou enfrentála de surpresa e desprevenida, o que lhes assegura menor risco na execução do intento. ${ }^{6}$ Paradoxalmente, muitos dos argumentos jurídicos em defesa do agressor recaem, predominantemente, sobre as "razões passionais" e de resguardo à honra masculina para explicar tais homicídios, uma vez que o sistema jurídico não assegura, necessariamente, a efetividade do emprego da lei em toda sua extensão formal e substancial de modo equivalente para homens e para mulheres.

Em outras palavras, o sistema jurídico, de modo geral, apresenta dinâmicas e conteúdos sexuados na interpretação e decifração de fatos e situações relativas à violência contra a mulher, reforçando a concepção tradicional de família e, consequentemente, da hegemônica divisão sexual do trabalho, do poder e das categorizações da sexualidade deslocadas do cotidiano para os espaços sociais mais amplos, caracterizados em esferas ou campos. Assim, as mulheres são controladas também socialmente pela sua inserção na cotidianidade da vida, na dedicação à família, à maternidade, aos filhos, nas disputas minúsculas do cotidiano, nos pequenos conflitos, como também nos valores como a fidelidade, honestidade, empatia, subjetividade e cooperação (Devreux, 2005).

Observa-se que a maioria da violência viril está relacionada ao fato de as mulheres não responderem plenamente ao padrão ideal de comportamento normativo a elas atribuído nas relações familiares. Essa incompatibilidade está na origem das razões "legítimas" que o marido/companheiro invoca para o uso de um ato corretivo e disciplinador:

No Brasil, a força da categoria relacional da "honra" funda a construção simbólica dos gêneros no que tem de mais impensado e naturalizado. A construção dos valores hegemônicos do masculino 
se faz em torno do desafio da honra, do controle das mulheres e da disputa entre os homens. [...] cabe ao homem tomar conta de sua mulher [...] é dever do homem [leia-se do macho] ficar de olho na sua mulher [leia-se propriedade]. (Machado, 2006, p. 1).

As mulheres ainda são vistas pelos homens - e muitas ainda se vêem -, na condição de parte integrante de um cenário dessimétrico e tradicional, com ausência de direitos individuais e subjetivos, restritas e inferiorizadas nos espaços e sistemas legais, assim como nas discursividades sociais. As falas abaixo exemplificam:

As pessoas precisam rever muitos valores. Por exemplo, há quem ache [alguns homens] que violência contra as mulheres é legítima em certas situações. Isso precisa ser discutido. Toda violência é, por princípio, ilegítima. $^{7}$

Nas oficinas com os homens, percebemos que a 'identidade masculina' vê a violência como algo quase natural, quase como sinônimo da masculinidade. Homem que é homem manda. $\mathrm{O}$ objetivo do nosso trabalho é desnaturalizar essa violência que vai desde obrigar a companheira a servir a comida até ter relações sexuais forçadas. ${ }^{8}$

Uma das razões do aumento da violência deve-se também à socialização violenta vivenciada pela transmissão intergeracional que se ancora na afirmação do ethos viril presente entre os iguais e entre os não iguais masculinos. A competição e a rivalidade estabelecidas entre homens de status similares e de status diferentes enfatizam as sociabilidades competitivas nos relacionamentos violentos entre os homens, geralmente antecedidos por conflitos abrigados no machismo e no sexismo:

Pai e filho se aliam contra desafeto. Manoel, 35 anos decidiu acertar as contas com um antigo desafeto na noite de domingo e como parceiro do crime escolheu o filho de 14 anos, ao qual deu um revólver calibre 38. O jovem puxou o gatilho várias vezes, atingindo a cabeça, o braço e a perna da vítima desafeta. Pai e filho compartilharam do ato da vingança. ${ }^{9}$ 
Como destacam Súarez e Bandeira (1999), são as interações sociais entre pai e filho que, aliados, garantem a manutenção dos espaços de poder, assim como perpetuam o código hegemônico de honra e de vergonha contido no dito popular: "homem que é homem (macho) não leva desaforo para casa". Esse processo é deslocado para as relações entre os gêneros, expressamente manifesto no controle viril, extensivo do cotidiano familiar aos espaços públicos e institucionais.

Portanto, concorda-se com Almeida (2007, p. 27), “... ao enfatizar que o conjunto complexo e contraditório destas relações que se potencializam mutuamente, coloca limites e abre possibilidades às práticas sociais dos sujeitos individuais e coletivos. Em outros termos, é no quadro dessas relações sociais e das desigualdades daí derivadas que se processam as práticas e as lutas sociais".

\section{Inovações institucionais e legislativas como estratégias de resistência feminista em relação à violência contra a mulher}

Faz 30 anos que as mulheres, inconformadas com a disseminação das práticas de controle e violência, criaram os pioneiros espaços de resistências, os SOS Corpo. ${ }^{10}$ Foram essas as primeiras organizações a denunciar a violência contra a mulher, sem qualquer apoio institucional, com atuações da sociedade civil organizada, crítica e propositiva, reivindicavam a tomada de consciência do Estado. Inúmeras campanhas lideradas pelo movimento feminista na década de 1980 trouxeram ao público a trágica situação de milhares de mulheres mortas em nome da "honra", da "submissão" e do "amor" por seus maridos, companheiros e amantes. Desde aquela época, ficaram cunhados os slogans "Quem ama não mata" e "Denuncie a violência contra a mulher", palavras de ordem das primeiras campanhas contra a violência. 
Em 1983, acompanhando as eleições dos primeiros governos democráticos, foi criado o primeiro Conselho da Condição Feminina em São Paulo e, logo em seguida, o do Estado de Minas Gerais e o Conselho Nacional dos Direitos das Mulheres (CNDM), em 1985. Associadas a essas iniciativas, várias ações foram institucionalizadas, com destaque para o movimento das mulheres que reivindicaram a criação, com o apoio do Ministério da Saúde, do Programa de Assistência Integral a Saúde da Mulher (PAISM). No entanto, a iniciativa que teve maior expressão e repercussão como política pública foi a Delegacia Especial de Atendimento à Mulher(DEAM), ${ }^{11}$ e representou um ganho político significativo, pois tornava o Estado também responsável pelo controle dessa violência.

A primeira DEAM foi criada em São Paulo, em 1985, seguida pela do Rio de Janeiro, em 1986. A vivência cotidiana nas DEAMs logo mostrou a necessidade de dinâmicas e estratégias de atendimento específicas, sobretudo por atender segmentos femininos mais populares, e de novos perfis de atuação profissional das/os agentes.

Se, por um lado, as DEAMs não se constituíram em uma realidade isolada, pois, estavam inseridas no processo de redemocratização política e do repúdio à violência de forma explícita, processo esse que influiu na elaboração da Constituição de 1988, por outro, assegurar a existência promissora dessas instituições estaria condicionado a ir muito além da "síndrome da queixa", deslocando a compreensão das/os agentes para as tensas dinâmicas da violência de gênero. Isso efetivamente acabou não ocorrendo, estagnou-se na idéia de que o corpo de agentes das DEAMs não poderia transcender de suas funções formais, e, portanto, não poderia assimilar nem a função das assistentes sociais, nem a das psicólogas. As/os agentes e delegadas/os destinadas/os à DEAM assumiam a nomeação mais como uma forma de intolerância, de desprestígio e até mesmo como um castigo, o que lhes causava mais desinteresse do que compromisso 
com o desempenho profissional, uma vez que deveriam servir-se das tipificações penais existentes, as quais não compreendiam as formas de violências contra a mulher. ${ }^{12}$

Nos 30 anos de sua existência, as DEAMs, além de produzirem um efeito político na sociedade, expressaram a legitimidade de que a violência contra a mulher é um problema amplo, de saúde pública, que envolve toda a sociedade brasileira. Assim, a reflexão crítica produzida sobre a "violência contra a mulher", envolvendo a atuação das DEAMs, pode destacar alguns elementos, resumidamente apontados por Suárez e Bandeira (2002):

a) Tomada de consciência sobre a natureza das sociabilidades violentas que permeiam as relações de senso comum na vida cotidiana das mulheres. Além de causarem dor e sofrimentos físicos e emocionais reais, essas violências minúsculas transcendem a realidade vivida, impregnam o imaginário e, ao mesmo tempo, interferem na própria realidade.

b) Importância das organizações de mulheres em processos grupais; o grupo de apoio às mulheres agredidas, como uma experiência inicial de apoio e estímulo, ajudava-as nas escolhas, seja em busca de coragem e autonomia, seja da necessidade de realizar a denúncia, incentivando-as a procurar a DEAM. Em outras palavras, ao estimular as capacidades de autoestima dessas mulheres, a atuação desses grupos dava-lhes, condição de autonomia para enfrentarem o medo e a perseguição, tornando-se mais livres.

c) A percepção de que a violência está presente, senão em todas, pelo menos na maioria das ações e relações sociais, interpessoais e coletivas é extensiva às instâncias públicas. No caso das DEAMs, a expectativa era de que as mulheres 
"vítimas" não fossem re-vitimizadas, à medida que as/os agentes mudassem o padrão de acolhimento e a cultura da escuta, o que poderia gerar, necessariamente, um aprendizado das/dos próprias/os agentes em relação ao seu desempenho.

d) A crítica elaborada abalou a crença de que a cidadania tem funções de integração social e que garante, ipso facto, a equidade social, regulando as violências interpessoais. Contra-argumenta-se que a cidadania, tal qual definida formalmente, não poderia absorver e regular os conflitos interpessoais, visto que estes estão mais enraizados nos costumes do que nas desigualdades sociais.

e) O assassinato de mulheres é considerado fato de extrema gravidade, enquanto que as minúsculas agressões cotidianas - quase sempre admissíveis - estabelecem novas regras de sobrevivência associadas aos conteúdos morais antigos e recentes que caracterizam o padrão de sociabilidade entre homens e mulheres e intragêneros (Machado da Silva, 1999).

\section{A Lei no 9.099/95 e a vulnerabilização dos crimes de violência contra as mulheres}

A capacidade da resistência feminista se caracterizou pelas críticas formuladas ao uso opressivo da Lei $n^{0}$ 9.099/95 às mulheres. Por sua vez, as DEAMs, na falta de uma jurisprudência específica para o combate da violência, passaram a servir-se dessa Lei como referência jurídica para tratar dos delitos de violência de gênero, sobretudo das lesões corporais e dos crimes de ameaça.

Se por um lado, é inegável que nas sociedades ocidentais contemporâneas os conflitos interpessoais tomaram tal magnitude 
nas sociabilidades da vida privada cotidiana que uma espécie de contrato social desigual e hierárquico dissimula as relações conjugais que conflitam com os ideais de igualdade universal de direitos entre homens e mulheres, por outro, esse contrato está presente nas sociabilidades e nas relações institucionais (Suárez, 2002) e também conseguiu se fazer presente no espírito da Lei $\mathrm{n}^{\circ}$ 9.099/95, conforme revela uma pesquisa sobre a violência contra a mulher realizada pelo Data Senado, em 2006/2007:

Perguntados sobre o que acham que ocorre quando a mulher faz a denúncia: $33 \%$ dos entrevistados afirmaram que "quando o marido fica sabendo, ele reage e ela apanha mais"; $27 \%$ responderam que não acontece nada com o agressor; $21 \%$ crêem que o agressor vai preso; enquanto $12 \%$ supõem que o agressor recebe uma multa ou é obrigado a doar uma cesta básica. ${ }^{13}$

Criada a Lei para "resolver" os minúsculos delitos da vida ordinária, a expectativa de celeridade e de ruptura com a impunidade - centrada na busca pela "conciliação" entre as partes e visando mais eficácia processual -, acabou transformada em celeiro para a "resolução" dos crimes de violência praticados contra a mulher. Assim a partir de 1995, os crimes comuns de violência denunciados nas DEAMs, tais como as lesões corporais e ameaças, passaram a ser tratados no âmbito da Lei ${ }^{0}$ 9.099/95, operada pelos Juizados Especiais Civis e Criminais (JECRIMs), destinados a julgar delitos considerados de menor potencial ofensivo. Ou seja, aqueles crimes de pena máxima não superior a dois anos. Não se trata de discutir aqui os efeitos dessa lei e as mudanças na política criminal repressiva brasileira, mas de enfatizar suas implicações no tratamento da violência contra as mulheres.

Campos (2001) e Barsted (2006) evidenciam os principais pontos polêmicos da Lei $n^{\circ}$ 9.099/95 que geraram insatisfações e resistência por parte do movimento feminista: a) os delitos de violência contra a mulher perderam o caráter de crimes de ação pública - qualquer pessoa podia denunciar - e foram transformados 
em crimes de ação pública condicionados à representação da vítima, o que significa que a ação penal só tem início a partir de denúncia expressada pela vítima de processar criminalmente o acusado; b) restrição na atuação da DEAM que, pela Lei no 9.099/95, tem função mais centrada no registro do Termo Circunstanciado de Ocorrência (TCO); c) a nova lei suprimiu a realização do inquérito policial, esvaziando, em parte, a competência investigativa das DEAMs; d) estabeleceu penalidades pecuniárias e trabalho alternativo, ambos bastante desacreditados como elementos punitivos em nossa sociedade; e) estabeleceu mecanismos quase "compulsórios" de conciliação entre as partes caracterizando a "imposição" de um "fim" ao conflito.

Se, por um lado, a Lei n ${ }^{\circ}$ 9.099/95 trouxe novas competências aos espaços de atuação jurídica dos JECRIMs, criados a partir de uma tríade articulada: celeridade dos procedimentos, intencionalidade relativa de promover a conciliação e atribuição de penas alternativa e/ou pecuniárias, por outro, a conseqüência imediata foi que, dos casos em que os JECRIMs passaram a atuar, cerca de $70 \%$ eram relativos à violência contra a mulher e, destes, mais de $50 \%$ das denúncias acabavam efetivando-se em "acordo de conciliação", assinado pelas partes. Portanto,

[...] levando-se em consideração a natureza da violência doméstica e a relação de poder presente nesses crimes, a Lei $n^{0}$ 9.099/95, ao incluir as ameaças e as agressões físicas no rol dos crimes de menor potencial ofensivo, acabou por estimular a desistência das mulheres, através das audiências de conciliação, de processar seus maridos ou companheiros agressores. Com isso reforçou, também, a cultura da impunidade que leva os homens a agredirem as mulheres. (Barsted, 2006, p. 78).

A Lei $n^{\circ}$ 9.099/95 ao tratar a violência contra a mulher na ordem semântica de menor potencial ofensivo, não ofereceu as soluções que as vítimas necessitavam, uma vez que a centralidade desta lei dirigia-se ao agressor-réu. As vítimas mulheres eram 
praticamente silenciadas mediante a pergunta: "a senhora quer continuar a discutir o assunto?” (Campos, 2001). Essa pergunta, profundamente inibidora e indutora de resposta, propiciava que, na continuidade da audiência, fosse apresentado o termo do acordo conciliatório para ser assinado, e, logo após, o casal regressava para casa, já reconciliado. Escondia-se por trás dessa conciliação, sem dúvida, a garantia da manutenção dos laços familiares, e, com isso, sucumbia a causa do conflito. Na realidade, acabava sendo destinada ao lócus familiar a responsabilidade de produzir a reconciliação do conflito entre as partes.

Além do efeito descriminalizante da Lei, uma das suas consequências perversas era o fato de, em muitas situações, a própria mulher, vítima da agressão, ter de trabalhar para pagar a cesta básica, uma vez que o marido, em muitos casos, encontrava-se desempregado quando retornava do ato conciliatório.

Assim, a partir de 2002, um consórcio ${ }^{14}$ composto por entidades públicas, ONGs, representantes do movimento feminista e grupos organizados interessados na questão uniu-se a uma parte da bancada feminina no Congresso e teve início o processo de elaboração de uma nova proposta de lei que, calcada na Convenção de Belém do Pará, enfrentasse a violência doméstica contra as mulheres de forma mais eficaz.

Em abril de 2004, o Executivo instituiu o Grupo de Trabalho Interministerial para “... elaborar proposta de medida legislativa e outros instrumentos para coibir a violência doméstica contra a mulher", sendo relatora do Projeto de Lei a então deputada Jandira Feghali. Depois de mais de um ano de diálogo e discussão com vários grupos feministas, entidades políticas e assessoras da Secretaria Especial de Política para as Mulheres (SPM/PR), e contando com a assessoria de advogados sensíveis à questão, chegou-se ao texto definitivo da nova lei de combate à violência contra a mulher. 
Vale destacar o depoimento do promotor Lessa Bastos (2007, p. 3) a propósito da Lei $n^{0} 9.099 / 95$ e da chegada da lei Maria da Penha:

A Lei $\mathrm{n}^{\mathrm{0}} 11.340 / 06$ pegou a comunidade jurídica de surpresa e, como tudo o que é novo, tem despertado bastante discussão, principalmente pelo afastamento dos institutos despenalizadores da Lei dos Juizados Especiais Criminais nos casos de violência doméstica e familiar contra a mulher (...) tendo em vista que o modelo dos Juizados Especiais Criminais, não tanto por suas regras, mas principalmente por sua operacionalização, se mostrou ineficiente e inadequado para o enfrentamento de um problema que, lamentavelmente, ocorre diuturnamente...

\section{A Lei Maria da Penha como estratégia de re-humanização do tratamento jurídico às mulheres}

Em vigor desde o dia 22 de setembro de 2006, a Lei $n^{\circ}$ 11.340/06 foi uma resposta do Congresso Nacional às expectativas da sociedade, com o intuito de reverter o tratamento que era dado às mulheres agredidas. Em 2006, a pesquisa realizada pelo Data Senado revelou que $95 \%$ das entrevistadas mulheres desejavam a criação de uma lei específica para protegê-las contra a violência doméstica.

Essa lei foi cunhada como Lei Maria da Penha em homenagemà biofarmacêutica Maria da Penha Maia, que, em 1983, por duas vezes, sofreu tentativas de assassinato pelo marido, professor universitário, e acabou ficando paraplégica. Lutou por 20 anos pela condenação de seu agressor, ingressando com um processo nas Nações Unidas, o qual despertou o Estado brasileiro para a gravidade da situação. Maria da Penha transformou sua dor em luta e sua tragédia em solidariedade com as mulheres brasileiras.

Em 2007, mesmo sem ter tido reflexo direto na diminuição dos casos de violência, a Lei $n^{\circ} 11.340$ já se tornara um mecanismo 
institucional capaz de indicar outra visibilidade para a questão, assim como de garantir mais proteção às mulheres, de acordo com $54 \%$ das entrevistadas pelo Data Senado.

$A$ Lei $n^{0} 11.340$ objetivou conferir cumprimento às obrigações contraídas pelo Brasil quando da ratificação da Convenção de Belém do Pará (1994) e re-definiu a natureza desse crime. A Lei prevê a obrigação de o Estado atuar preventivamente contra expressões de violência por meio da inclusão das agredidas em programas sociais, reconhecendo as distintas vulnerabilidades existentes e facilitando o acesso das vítimas à justiça e às necessárias medidas preventivas de urgência, muitas delas no campo do direito de família, para deter a escalada da violência contra as mulheres. Ainda estabelece iniciativas inéditas para enfrentar a violência, como a criação de uma Vara Judicial para atender mulheres agredidas, interferindo na área da segurança pública e no Judiciário, buscando contribuir para mudar práticas institucionais e de atuação dos/as agentes públi$\cos$ as no enfrentamento dessa questão. Há consenso de que a Lei Maria da Penha veio para responder às impropriedades da Lei $n^{\circ}$ 9.099/95, no seu uso em relação à violência contra as mulheres.

No contexto da Lei Maria da Penha pode ser destacado o artigo $5^{\circ}$ que adota a definição de violência contra a mulher do artigo $1^{\circ}$ da Convenção de Belém do Pará e ressalta o âmbito de sua aplicação quando ocorrida:

I - no âmbito da unidade doméstica, compreendida como espaço de convívio permanente de pessoas, com ou sem vínculo familiar, inclusive as esporadicamente agregadas;

II - no âmbito da família, compreendida como relações pessoais afetivas;

III - em qualquer outra relação pessoal de afeto na qual o acusado compartilhe, tenha compartilhado ou não o mesmo domicílio ou residência da ofendida. 
Ressalte-se que são bastante adequadas as definições desse artigo. Contudo, no que se refere ao inciso II, dever-se-ia entender que o âmbito da família compreende também as relações decorrentes de parentesco civil ou natural, e, portanto, não sendo somente compreendida como relações pessoais afetivas. No que a Lei inova?

a) amplia o conceito de violência de gênero;

b) incorpora a perspectiva psicológica, autodepreciativa que está na base dos atos violentos mais graves e que envolvem a condição moral;

c) ataca a violência enraizada em uma cultura sexista secular que mantêm a desigualdade de poder que permeia as relações entre as agredidas e os agressores, cuja origem não está na vida familiar/doméstica, mas que faz parte das estruturas sociais mais amplas;

d) traz inovações em relação ao código penal;

e) os processos e os julgamentos relativos à violência devem ter preferência nas varas criminais, o que indica uma preocupação não apenas com a celeridade, mas também com o sofrimento, o que propicia melhores condições para a conscientização da condição feminina;

f) determina que o Estado crie mecanismos e estratégias para proteger as mulheres, além da implementação de redes de serviços interinstitucionais, promoção de estudos e estatísticas, assim como a implementação de centros de atendimento multidisciplinar;

g) determina, para os agressores, o comparecimento obrigatório a programas de recuperação e prevê medidas de proteção à vítima da violência; 
h) amplia o conceito de sexualidade, contemplando a violência ocorrida nas uniões homoafetivas, pois estas também constituem entidade familiar.

Em recente depoimento público dado pela ministra Nilcea Freire, da Secretaria Especial de Política para as Mulheres, destacase:

Levantamento realizado nas Delegacias Especializadas de Atendimento à Mulher (DEAMs) apurou que no ano de 2005, apenas nas capitais brasileiras, houve cerca de 55 mil registros de ocorrências. $\mathrm{O}$ índice salta para 160.824 mil se consideradas as demais cidades. Esses dados, todavia, tornam-se ainda mais significativos por corresponderem a apenas $27 \%$ das DEAMs existentes e pelo fato de um número significativamente alto de mulheres não recorrer à autoridade policial por medo, vergonha $\mathrm{e}$ falta de crença na eficácia de sua denúncia. ${ }^{15}$

A violência contra a mulher não é um "evento" considerado excepcional para os segmentos femininos populares. Trata-se de uma prática que redimensiona ou renegocia os pactos domésticos e, nesse sentido, há elementos distintivos entre as mulheres agredidas, os quais passam, sobretudo, pela condição de classe, raça/etnia e não podem ser omitidos.

Há vários tipos de críticas em relação à viabilidade e aplicabilidade da Lei Maria da Penha. Nessa contramão são colocados vários "obstáculos". Argumenta-se que o maior rigor da lei pode inibir as denúncias de maus tratos por parte das mulheres, já que agora os maridos sabem que podem ser presos: "Eu só não te dou um tapa na cara por causa da lei nova do Lula e eu posso ser preso", disse o parceiro de uma das mulheres assistidas pela Casa Cidinha Kopcack, que atua na Zona Leste da capital paulista. ${ }^{16}$ Há outras que questionam quais seriam os limites de intervenção das esferas jurídicas na vida das mulheres! Ainda criticam a Lei, no sentido de que esta não estaria ilesa ao fato de que a justiça jamais 
considera a condição de igualdade entre homens e mulheres, pois não seria neutra em seus julgamentos, mesmo que formalmente seja regida pelos princípios universais.

A Lei assegura que quando uma mulher é agredida, não importa como ou onde, esse ato passa a ser um problema para o Estado e não é mais da esfera privada, cujos encaminhamentos devem ser providenciados. Daí a ênfase da Lei Maria da Penha nas estratégias preventivas. Também a nova legislação não remete mais ao pagamento de pena pecuniária, pelo delito ocorrido; ao contrário, permite que agressor seja preso em flagrante ou que tenha a prisão preventiva decretada.

Qualquer avaliação do desempenho da Lei Maria da Penha é ainda prematura. No entanto, algumas análises estatísticas apontam que o volume de queixas nas 128 delegacias da mulher no Estado de São Paulo caiu em 18\% no ano que se seguiu à entrada em vigor dessa lei, em setembro de 2007. Isso talvez seja devido tanto ao maior rigor anunciado para os agressores, como ao inegável receio em denunciar, seja em função das represálias, seja pelo desconhecimento das consequências trazidas pela Lei (Ribeiro, 2007).

Quanto aos agentes públicos formadores do corpus jurídico, as questões relativas à implantação plena da lei parecem mais complexas. Segundo afirmação de Lessa Bastos (2007), promotor de Justiça do Rio de Janeiro:

[...] não por culpa do legislador, ressalva-se, mas, sem dúvida, por culpa do operador do Juizado, leiam-se, Juízes e Promotores de Justiça - que, sem a menor cerimônia, colocaram em prática uma série de enunciados firmados sem o menor compromisso doutrinário e ao arrepio de qualquer norma jurídica vigente, transmitindo a impressão de que tudo se fez e se faz com um pragmatismo encomendado simplesmente e tão-somente para diminuir o volume de trabalho dos Juizados Especiais Criminais. E o pior: não satisfeitos com isto e alheios ao autêntico "cartão vermelho" imposto aos Juizados Especiais Criminais pela Lei Maria da Penha, Juízes do 
Estado do Rio de Janeiro, reunidos em Búzios este mês de setembro, reafirmaram aqueles enunciados, agregando outros decorrentes da "análise" da Lei Maria da Penha - que, em resumo, poderiam ser sintetizados no seguinte: "considerando que não nos agradou, fica revogada a Lei n ${ }^{\circ} 11.340 / 06 "$ ".

O maior desafio é institucional e apresenta-se em dois níveis. No primeiro, relativo aos processos de mudança nos paradigmas disciplinares no campo jurídico de formação universitária e profissional, atinge as mentalidades, os valores e as idéias. No segundo, em direção à democratização das relações sociais de gênero no campo da atuação jurídica, atinge a constituição de uma vontade política. Inversamente, em proporções similares, está a dificuldade de a mulher romper com a violência e do homem romper com o papel idealizado de dominador porque “... só quando fica insuportável é que a mulher quebra a barreira do silêncio e denuncia". ${ }^{17}$

Ademais, em pleno acordo com Campos (2008, p. 2-3) quando afirma:

A relutância em aplicar a Lei Maria da Penha talvez possa ser explicada pelo desconhecimento da violência de gênero em nossa sociedade e pelo senso comum teórico dos juristas (Warat). Ao desconhecerque a violência é estruturante das relações hierarquizadas entre os sexos, os operadores do direito desconhecem que ela produz uma vulnerabilidade específica. É exatamente essa situação que torna a natureza da violência doméstica distinta de todos os demais delitos. Esse desconhecimento tem como consequência decisões inadequadas que acabam por sustentar a aceitação social da violência contra as mulheres.

Assim, a implementação dessa Lei dependerá dos seguintes fatores: 1) capacitação adequada dos/as agentes jurídicos/as; 2) vontade política; 3) recursos materiais; 4) intenções pedagógicas dos operadores do Direito, pois a Lei implica mudanças substantivas e formais; 5) criação simultânea de serviços jurídicos imprescindíveis 
para o funcionamento de uma política pública para apoiar e proteger mulheres em situação de violência.

\section{Normas da atuação da prática jurídica ou necessidade de refazer uma dialética dos costumes?}

É sabido que a preservação do modelo tradicional de relação masculino-feminino e familiar sustenta-se, ainda, nos ideais conservadores predominantes em nossa cultura, na esfera familiar, os quais se fazem presentes também na conduta de agentes públicos masculinos no âmbito das instituições - o sistema judiciário, por exemplo -, e que se consideram as questões relativas à violência doméstica como assunto da vida privada.

Nesse sentido, para se tentar entender o paradoxo: mais lei e mais violência contra as mulheres, é necessário refazer uma dialética dos costumes, que atinge boa parte dos operadores do direito, para as quais a mulher é vista como dependente do padrão consagrado da conduta masculina vigente. Para Chauí (2001), o padrão simbólico do homem brasileiro pacífico e ordeiro, do homem cordial de Sérgio Buarque de Holanda (1991) ainda predomina e pode ser - em sua extensividade - metafórico ao horizonte do judiciário, não apenas porque a questão da violência contra a mulher é remetida ao âmbito da privacidade, mas porque vale o peso da família, sobretudo em seus moldes tradicionais ${ }^{18}$ e também porque persiste a crença de que, se o homem bate na mulher, é porque ou ela gosta de apanhar ou ela merece - e o cancioneiro popular é pródigo em exemplos de que o homem age assim para exercitar seu dever de aplicar um corretivo.

A força da representação mítica de que "somos um povo pacífico, ordeiro e inimigo da violência" (Chauí, 2001, p. 8) e do homem cordial (Holanda, 1991) - discursos que se ancoram na 
crença, segundo a qual bater em mulher não pode se constituir em crime - explica, em boa medida, a não estranheza e a tolerância para os mais de 150 mil registros de violências contra as mulheres contabilizados, anualmente, no Brasil. A força de valores viris tradicionais é sempre renovada em representações que se atualizam nas raízes fundadoras do Brasil:

Se também dizemos mito fundador é porque, à maneira de toda fundatio, esse mito impõe um vínculo interno com o passado que não cessa nunca, se conserva permanentemente presente $\mathrm{e}$, por isso mesmo, não permite o trabalho da diferença temporal e da compreensão do presente enquanto tal. Nesse sentido também se fala de um mito psicanalítico, ou seja, como impulso à repetição de algo imaginário que cria um bloqueio à percepção da realidade e impede de lidar com ela. (Chauí, 2001, p. 9).

Perdura no imaginário brasileiro a representação desse homem cordial, ordeiro e não violento, e se, por alguma "eventualidade", agride a mulher, ele age imbuído de seu papel de disciplinador. Há aí uma dialética perversa, pois esses valores tão arcaicos são reatualizados nos lugares simbólicos e nas formas de interpretação jurídica. Essas representações perduram há séculos, uma vez que, segundo Oliveira (2002, p.109), "Kant já reafirmava que a prevalência da autoridade masculina não prejudica a igualdade, pois é derivada da superioridade de gênero, expressamente admitida como natural em relação ao gênero feminino".

Em parte, o pensamento e a atuação dos operadores do direito têm caminhado em direção diversa ao que propõe o pensamento feminista, uma vez que, ao se referirem à especificidade da violência doméstica e familiar, eles tendem a não tratar a agredida como indivíduo, dando prioridade à família, ao lar, e, portanto, maximizam o significado da ordem familiar como uma ordem "natural" regida pelo homem-provedor. 
Essas representações - que sustentam a harmonia familiar - estão presentes na aplicação da justiça, interferem nos autos de defesa da integridade física da mulher e a favor de seus direitos individuais. Evidentemente, para os operadores do direito - juízes e promotores e os outros agentes públicos - essa lógica está associada à idéia de que interferir na vida privada e na intimidade das pessoas não seria parte de sua função judicial, o que permite compreender, em boa medida, a manutenção dessa racionalidade familista e de suas implicações para as relações sociais de gênero.

Mulheres abstratas e genéricas constituem a referência para os juristas, desconsiderando suas múltiplas especificidades, uma vez que toda a dinâmica processual é colocada a partir do fato conflito ou violência -, sem ter primazia a condição representacional do sistema de gênero tradicional, ainda estruturador das instituições públicas. Isto quer dizer que as mulheres são consideradas como uma categoria/tipo e não como sujeitos específicos. Há necessidade de torná-las juridicamente inteligíveis.

O inexplicável. Tente explicar para um estrangeiro que não saiba nada de Brasil o que é o caso Pimenta Neves. Eu não consegui, porque é inexplicável, que um homem que matou uma moça 30 anos mais nova, de forma premeditada, por motivo torpe, réu confesso, condenado pelo Tribunal do Júri, receba, seis anos depois, o benefício de continuar aguardando em liberdade. (Leitão, 2006, p. 3).

Há muita dificuldade em se entender as racionalidades que norteiam a esfera do judiciário, ao mesmo tempo em que obter informações no contexto judiciário é difícil: são indisponíveis e escassos os dados e informações sobre a atuação de categorias jurídicas específicas em relação às sentenças. Por exemplo: os membros do poder judiciário não são acessíveis à realização de entrevistas; por sua vez, o sistema de informação de dados e de registros policiais é impreciso e não há registros que caracterizam 
vítimas e agressores para além das variáveis tradicionais. Outra dificuldade refere-se à falta de tipificação dos crimes de violência contra a mulher nos Códigos, o que possibilita um uso interpretativo e estigmatizante.

Estamos percebendo que ser homem também não é muito fácil, porque nos pautamos por um modelo preestabelecido. Desfazer esse modelo é, ao mesmo tempo, abrir mão de certos privilégios. Só que esses privilégios não são tão privilégios assim. Ter o poder acaba nos vitimizando também. ${ }^{19}$

Faz-se necessário articular direito universal e direito específico ou diferenciado, mediante o convencimento das autoridades de que $o$ atendimento especializado e diferenciado deve ser dado à questão da violência contra as mulheres para que se alcance a igualdade de direitos universais entre homens e mulheres. A meu ver, isso depende de dois fatores: a) investimento mais sistemático e articulado entre as agendas feministas com as instituições de segurança pública e o judiciário; b) cursos de capacitação para o pessoal das DEAMs e para o Judiciário articulados com a montagem de redes de serviços para as mulheres em situação de violência.

Diante desse cenário, a Lei Maria da Penha pode ter efeitos não previsíveis para as mulheres, uma vez que tem sido objeto de (in)compreensão por parte dos operadores do direito, e

(...) o reconhecimento de uma vulnerabilidade específica (a violência praticada por parceiro íntimo) é marca distintiva da Lei (...) $\mathrm{O}$ tecnicismo jurídico para negar validade à Lei Maria da Penha é exemplo de um cinismo jurídico, o mesmo cinismo que criou a tese da legítima defesa da honra para absorver homicidas (...) A busca pela igualdade de gênero requer o reconhecimento desta desigualdade fática alimentada pelo cotidiano da violência doméstica. A Lei Maria da Penha acolhe essa desigualdade e protege as mulheres na exata medida em que elas, ao acionarem o Poder Judiciário, reconhecem-se enquanto sujeito de direitos. (Campos, 2007, p. 4). 


\section{A ideologia da conciliação no Judiciário}

Há estudos em desenvolvimento sobre o que tem significado "a ideologia da conciliação" (Bandeira; Thurler, 2007), cada vez mais predominante na prática característica da atuação dos operadores do Direito em relação aos processos da violência contra a mulher.

Diante das situações de violência de gênero, por que o Judiciário se empenha em promover a "conciliação" entre o casal? Estaria o significado da conciliação, para além da des-responsabilização do poder público, também em devolver a responsabilização da situação de violência à esfera do privado, para que o casal busque soluções? Aceitar a conciliação seria a única opção proposta para as mulheres? Outra "solução" seria submeter as mulheres a um processo "terapêutico", o que pode significar colocá-las em um processo de convencimento de que a melhor alternativa seria a de perdoar!

As mulheres são agredidas, correm riscos de morte, muitas vezes têm de abandonar sua casa, filhos, emprego, parentes, pertences e, até mesmo, fugir ou desaparecer. No geral, passada a fase do pagamento de cesta básica, os agressores permanecem soltos. E, quando presos, não há nenhuma garantia de que serão mantidos, por tempo razoável, na prisão. A pergunta permanece: "conciliar", na área de família, é possível?

Ser homem ou ser mulher, muito mais do que uma determinação biológica, é uma questão ligada a modelos culturais impostos e idealizados por um grupo social dominante. Fala-se sobre um mundo onde as pessoas têm valor e poder desiguais, não apenas da perspectiva de gênero, mas também quanto a outras perspectivas a ela associadas: raça/etnia, classe, situação geracional, regionalidade. A essa realidade, que se desdobra e mesmo se espelha no âmbito das instituições, o Judiciário não está ileso. 


\section{Considerações finais}

Construir estratégias de resistência para o enfrentamento das práticas de violências contra as mulheres é uma tarefa de extrema complexidade que engloba dois aspectos principais: 1) promover mudanças nos micropoderes e nas subjetividades masculina e feminina; 2) capacitar os/as agentes para o atendimento às mulheres nas DEAMs, nas delegacias comuns, na rede de serviços e no sistema judiciário. Esses dois aspectos estão relacionados com o entendimento da relevância da violência contra as mulheres como uma questão sociopolítica, de segurança e de justiça.

Nas relações interpessoais, não mudaram as lógicas que articulam os espaços privado e público: no primeiro, os homens continuam violentos e, no segundo, eles continuam mandando. Apesar da existência da lei, ao ser aplicada por operadores do direito que mantêm as mesmas práticas e prerrogativas sociais, corre-se o risco de que sua eficácia acabe se esvaziando.

Há mais de três décadas, as pesquisas feministas na área das ciências sociais evidenciaram lógicas institucionais, jurídicas e políticas subjacentes aos sistemas sociais que negam à maioria das mulheres um estatuto de cidadania pleno e, consequentemente, de humanidade, uma vez que a sexualidade feminina, real ou suposta, tem sido frequentemente utilizada e apropriada como instrumento de controle viril e social que, para além do corpo, atinge também a subjetividade feminina.

Nesse sentido, faz-se necessário questionar os controles masculinos, institucionais e jurídicos sobre as práticas sexuais femininas consideradas "à margem" (estigmatizantes) em relação à definição da norma heterossexual no domínio das sexualidades e das convivências intersubjetivas entre mulheres e homens, tanto perante a lei como nos relacionamentos. Essas convivências incidem sobre as expressões de violências de gênero e sabe-se que quando as mulheres 
decidem recorrer ao Poder Judiciário é porque entendem ser esse o último recurso para cessar os ciclos de violência. Afinal, perguntase Campos (2007, p. 3): Quem irá responder pela irresponsabilidade do Poder Judiciário? Quem responde pela morte de uma mulher que teve negados os seus direitos?

\section{Notas}

1 Por sua vez, a Convenção Interamericana, ratificada pelo Brasil em 1994, se constituiu no marco que teve papel fundamental para pressionar o Estado a lograr mudanças legislativas, demandando políticas públicas de prevenção e atenção às mulheres vítimas (cf. Herman, Barsted, 1999, 2006).

2 Categoria utilizada por Marcela Lagarde (1992), Alicia Elena Pérez Duarte y Noroña (2006), assim como por Rita Segato (2006), o termo feminicídio indica o assassinato com crueldade de mulheres, em razão de seu sexo, e pode envolver também motivação política.

3 Matéria publicada nacionalmente por outros veículos, além do jornal Correio Braziliense.

4 No geral, os agressores referem-se às mulheres agredidas usando expressões do tipo: "mulher breteira", "pistoleira", "prostituta", "galinha", "sapatão", "lésbica" entre outras denominações desqualificadoras.

5 Somente em 1962, o Estatuto da Mulher Casada retira-lhe a condição de ser parcialmente incapaz, que a obrigava a pedir autorização ao marido para trabalhar, além de outras obediências.

6 Assim aconteceu com muitos casos noticiados. Porém, um de grande repercussão foi de Pimenta Neves, jornalista conhecido e prestigiado, que matou a jovem Sandra Gomide, em um haras no município de Ibiúna (SP), quando a moça se encontrava em momento de lazer e não esperava ser assassinada. 
7 Simone Diniz, médica e coordenadora do Coletivo Feminista Sexualidade e Saúde em São Paulo. Citação disponível em: <http:/ copodeleite.rits.org.br/apc-aa-patriciagalvao/home/index.shtml>.

8 Sérgio Barbosa, do Pró-Mulher, Família e Cidadania. Citação disponível em: $\quad<$ http:/copodeleite.rits.org.br/apc-aa-patriciagalvao/home/index. shtml?x=94>. Pesquisas realizadas indicam que de 2004 a 2006 aumentou a preocupação da população com a violência doméstica em todo o Brasil. Nas Regiões Norte e Centro-Oeste, atingiu o patamar de $62 \%$. Nas Regiões Nordeste, Sudeste e Sul, os índices foram superiores à preocupação com o desemprego: em torno de $70 \%$. Nas grandes capitais estaduais, aumentou de 43\%, para 56\% (cf. Ibope, Instituto Patrícia Galvão, 2007).

9 Jornal Correio Braziliense, Brasília, 20 dez. 2005. Caderno Cidades, p.12.

10 O pioneiro grupo de apoio denominado SOS Corpo apareceu em Recife, em 1978, e depois, o SOS Mulher, em São Paulo, em 1980.

11 Embora tenham sido criados no mesmo ano, o Conselho Nacional dos Direitos da Mulher data de 10 de setembro de 1985 e precedeu a criação da $1^{\text {a }}$ DEAM, no Brasil.

12 Vale lembrar que, em 1993, na primeira pesquisa realizada na DEAM criada em 1986, em Brasília, os registros dos delitos eram restritos apenas a oito categorias/tipificações, de acordo com o Código Penal. Em 2006, quando se retornou a coleta de dados, os registros (Boletins de Ocorrência) compreendiam mais de 40 tipificações registradas. Daí podem decorrer duas hipóteses: a) houve uma interpretação das/os agentes em relação ao dito; b) as/os agentes passaram a registrar as queixas a partir da narrativa das mulheres agredidas. Nas duas hipóteses prevalece a expectativa de que as/os agentes públicas/os tinham parcos conhecimentos sobre as dinâmicas da violência de gênero.

13 Disponível no sítio do Senado Federal, Secretaria de Pesquisa e Opinião Pública: <http://www.senado.gov.br>.

14 Entidades que formaram o Consórcio: SPM/PR, Cepia, Cfemea, Agende, Advocaci, Cladem/IPÊ, e Themis. Destacaram-se os assessores Rosane 
Reis Lavigne - defensora pública do Estado do Rio de Janeiro; Leilah Borges da Costa - advogada, membro do Instituto dos Advogados Brasileiros; Ela Wiecko de Castilho - procuradora federal; e Letícia Massula - advogada. Na tramitação do Projeto de Lei, outras ONGs, pesquisadoras, operadores do direito e militantes do movimento de mulheres contribuíram para a sua aprovação.

15 O depoimento dado pela Ministra Nilceia Freire encontra-se no Portal Violência contra a Mulher, do Instituto Patrícia Galvão/Fundação Ford.

16 Depoimento de Ivone Dias, coordenadora da Casa Cidinha Kopcak, citado por Ribeiro (2007).

17 Marta Rocha, delegada e presidente do Conselho da Mulher no Rio de Janeiro, em entrevista à revista $I s t o E ́$, São Paulo, n. 1812, reportagem de capa, seção Brasil, 30 jun. 2004. Citação disponível em: $<$ http:// www.patriciagalvao.org.br/apc-aa-patriciagalvao/home/noticias. shtml? $x=94>$.

18 Idéia exposta por Antonio Candido, que escreveu: "O significado de Raízes no Brasil", prefácio da obra escrita em dezembro de 1967, de Sérgio Buarque de Holanda.

19 Sérgio Barbosa, do Pró-Mulher, Família e Cidadania. Citação disponível em: $<$ http://www.patriciagalvao.org.br/apc-aa-patriciagalvao/home/ noticias.shtml? $\mathrm{x}=94>$.

\section{Three decades of the feminist resistance against sexism and violence towards women: 1976 to 2006}

Abstract: This paper analyzes the main actions and resistance strategies unchained by the Brazilian feminist movement that, in the last thirty years, tried to eradicate violence against women. It discusses on one side, the violence as a control strategy on the female body and, on the other, the inefficacy of the Law N. 9,099/95. With the implementation of Maria da Penha's Law, an important legislative and juridical conquest in the struggle against violence towards 
women, changes are evidenced in the sociocultural strategies and in the juridical resources used in the country; however, expressions of institutional violence are still present in the culture and in the juridical practices. Such expressions are part of a male moral logic that still models the dominant procedures and that are present in the institutions and among public agents, as well as in the private sphere and in the family, in other words, in all Brazilian society.

Keywords: feminist resistance, violence, gender, juridical culture, sexism, Maria da Penha's Law.

\section{Referências bibliográficas}

ALMEIDA, Suely Souza de. Essa violência mal-dita. In: ALMEIDA, Suely Souza de (Org.). Violência de gênero e políticas públicas. Rio de Janeiro: Ed. da UFRJ, 2007.

BANDEIRA, Lourdes. Patriarcado e violência masculina: crimes de morte como construção pública. Brasília, 2007. [Não publicado].

BANDEIRA, Lourdes; ALMEIDA, Tânia Mara C. de. A violência contra as mulheres: um problema coletivo e atual. In: LEOCÁDIO, Elcylene; LIBARDONI, Marlene (Orgs.). O desafio de construir redes de atenção às mulheres em situação de violência. Brasília: Agende, 2006.

BANDEIRA, Lourdes; THURLER, Ana Liési. As mulheres e a conciliação. Brasília, 2007. Dsiponível em: <http://copodeleite.rits.org.br/apcaa-patriciagalvao/home/noticias.shtml? $\mathrm{x}=679>$.

BASTOS, Marcelo Lessa. Violência doméstica e familiar contra a mulher. Disponível em: http://www.patriciagalvao.org.br/apc-aapatriciagalvao/home/noticias.shtml? $\mathrm{x}=515$. Acesso em: $17 \mathrm{mar}$. 2007.

BRANDÃO, Elaine Reis. Renunciantes de direitos? A problemática do enfrentamento público da violência contra a mulher: o caso da Delegacia da Mulher. Physis: Revista de Saúde Coletiva, Rio de Janeiro, v. 16, n. 2, p. 207-231, semestral, 2006. 
CAMPOS, Carmen Hein de. Maria da Penha: lei protege as mulheres na medida certa. Revista Eletronica Consultor Juridico, São Paulo, 22 ago. 2008. Disponível em: <http://www.conjur.com.br/static/ tex/69175,1>.

CASTILLO-MARTÍN, Márcia; OLIVEIRA Suely de. Marcadas a ferro. Brasília: Secretaria Especial de Política para as Mulheres, 2005.

CHAUÍ, Marilena. Brasil: mito fundador e sociedade autoritária. São Paulo: Perseu Abramo, 2001.

. Conformismo e resistência: aspectos da cultura popular no Brasil. São Paulo: Brasiliense, 1986.

DEVREUX, Anne-Marie. A teoria das relações sociais de sexo: um quadro de análise sobre a dominação masculina. Sociedade e Estado, Brasília, v. 20, n. 3, set./dez. 2005.

DUARTE, Marcela. Em meio minuto. Correio Braziliense, Brasília, 7 fev. 2007, Caderno Cidades, p. 25.

DUARTE y NORONHA, Alicia Elena Pérez (Coord.). Diagnóstico de violência feminicida em México, 2005: análisis de la impunidad em la violência feminicidia. Comisión Especial para Conocer e Dar Seguimento a las Investigaciones Relacionadas con los Feminicidios em la República Mexicana y a la Procuración de Justicia Vinculada. Ciudad de México, 2006. [Não publicado].

DUPLO homicídio em Planaltina. Correio Braziliense, Brasília, p. 31, 4 nov. 2008.

DURHAM, Eunice. A família operária: consciência e ideologia. Dados: Revista de Ciências Sociais, Rio de Janeiro, v. 23, n. 2, p. 201-213, 1980.

HERMANN, Jacqueline. A violência contra a mulher em números: dificuldades e desafios. In: LEOCÁDIO, Elcylene; LIBARDONI, Marlene (Orgs.). O desafio de construir redes de atenção às mulheres em situação de violência. Brasília: AGENDE, 2006. 
HERMANN, Jacqueline; BARSTED, Leila Linhares. La Convención de Belém do Pará: cinco años despues - uma revision de la implementación de la Convención Intermaricana para Prevenir, Sancionar y Erradicar la Violencia contra la Mujer. ICCLR, Ilanud, 1999.

HERMANN, Jacqueline; BARSTED, Leila Linhares. A violência contra a mulher no Brasil e a Convenção de Belém do Pará dez anos depois. In: PERES, Andrea (Coord.). O progresso das mulheres no Brasil. Brasília: UNIFEM, Fundação Ford, Cepia, 2006.

HOLANDA, Sérgio Buarque. Raizes do Brasil. Rio de Janeiro: José Olympio, 1991.

IBOPE; INSTITUTO PATRÍCIA GALVÃO. Percepção e reações da sociedade sobre a violência contra a mulher. Pesquisa nacional realizada em maio de 2006. Disponível em: $<\mathrm{http}: / /$ copodeleite.rits. org.br/apc-aa-patriciagalvao/home/noticias.shtml?x=527>.

INSTITUTO BRASILEIRO DE DIREITO DE FAMÍLIA (IBDFAM). Disponível em: <www.ibdfam.com.br $>$.

LACERDA, Ângela. Pernambuco é o Estado onde mais morrem mulheres no País. O Estado de São Paulo, Caderno Cidades, 16 mar. 2007 Disponível em: <http://www.estadao.com.br/ultimas/cidades/ noticias/2007/mar/16/193.htm>.

LAGARDE, Marcela. El feminicidio. México: Universidad Autónoma de México, 1992.

LARRANDART, Lucila. Control social, derecho penal y gênero. In: BIRGIN, Haydée (Comp.). Las trampas del poder punitivo: el género del Derecho Penal. Buenos Aires: Biblos, 2000.

LEITÃO, Miriam. O inexplicável. O Globo, Rio de Janeiro, 19 dez. 2006. Disponível em: <http://clipping.planejamento.gov.br/Noticias. asp?NOTCod $=327381>$.

MACHADO, Lia Z. Violência doméstica contra as mulheres no Brasil: avanços e desafios ao seu combate. Brasília, 2006. [Não publicado]. 
MACHADO, Lia Z. Atender vitimas: criminalizar violências, dilemas das Delegacias da Mulher. Brasília: UnB, Departamento de Antropologia, 2002. (Série Antropológica, n. 319).

MACHADO DA SILVA, Luiz Antonio. Violência e sociabilidade: tendências da atual conjuntura urbana no país. Rio de Janeiro: IUPERJ, IFCS/UFRJ, 1996. [Não publicado].

MENEGHEL, Stela N.; FARINA; Olga; RAMÃO, Silvia R. História de resistência de mulheres negras. Estudos Feministas, Florianópolis, v. 7, n. 1-2, 1999.

MULHER assassinada por ex-companheiro. Correio Braziliense, Brasília, p. 5, 10 mar. 2007.

OLIVEIRA, Rosa Maria Rodrigues de. Para uma razão crítica da razão androcêntrica: gênero, homoerotismo e exclusão da ciência jurídica. Caderno Themis: Gênero e Direito, Porto Alegre (RS), v. 3, n. 3, 2002.

PORTAL DA VIOLÊNCIA CONTRA A MULHER. Instituto Patrícia Galvão. Disponível em: <www.patriciagalvao.org.br>; <http:// copodeleite.rits.org.br/apc-aa-patriciagalvao/home/index.shtml $>$.

RIBEIRO, Sílvia. Registros de violência caem em delegacias da mulher após Lei Maria da Penha. G1 Portal Globo, 8 mar. 2007. Disponível em: <http://g1.globo.com/Noticias/0,,MUL9791-5605,00.html>; $<$ http://copodeleite.rits.org.br/apc-aa-patriciagalvao/home/noticias. shtml? $=672>$.

SEGATO, Rita Laura. Que és un feminicídio: notas para un debate emergente. Brasília: UnB, Departamento de Antropologia, 2006. [Não publicado].

. Las estructuras elementales de la violencia: ensayos sobre género entre la antropología, el psicoanálisis y los derechos humanos. Buenos Aires: Universidad Nacional de Quilmes, 2003.

- Antropologia e direitos humanos: alteridade e ética no movimento de expansão dos direitos humanos. Mana, Estudos de 
Antropologia Social, Rio de Janeiro, v. 12, n. 1, p. 207-236, abr. 2006. Disponível em: <http://www.scielo.br/pdf/mana/v12n1/ a08v12n1.pdf>.

SOIHET, Rachel. Condição feminina e formas de violência: mulheres pobres e ordem urbana 1890-1920. Rio de Janeiro: Forense Universitária, 1989.

SUÁREZ, Mireya; BANDEIRA, Lourdes. A politização da violência contra a mulher e o fortalecimento da cidadania. In: BRUSCHINI, Cristina; UNBEHAUM, Sandra (Orgs.). Gênero, democracia e sociedade brasileira. São Paulo: Fundação Carlos Chagas, Editora 34, 2002.

ZAFFARONI, Eugenio Raúl. El discurso feminista y el poder punitivo. In: BIRGIN, Haydée (Comp.). Las trampas del poder punitivo: el género del Derecho Penal. Buenos Aires, 2003. 